\title{
Magnet Dislocation: An Increasing and Serious Complication Following MRI in Patients with Cochlear Implants
}

\section{Magnetdislokation - eine zunehmende und folgenreiche Komplikation nach MRT bei Patienten mit Cochlea Implantat}

Authors

Affiliations
F. Hassepass ${ }^{1}$, V. Stabenau' ${ }^{1}$, S. Arndt ${ }^{1}$, R. Beck' ${ }^{1}$, S. Bulla ${ }^{2}$, T. Grauvogel ${ }^{1}$, A. Aschendorff ${ }^{1}$

Department of Otorhinolaryngology-Head and Neck Surgery, University Medical Center Freiburg

Department of Diagnostic Radiology, University Medical Center Freiburg

\author{
Key words \\ - head/neck \\ - MR imaging \\ - conventional radiography \\ - instrumentation \\ - safety
}

received $\quad 6.8 .2013$

accepted $\quad 24.10 .2013$

Bibliography

DOI http://dx.doi.org/

10.1055/s-0033-1356238

Published online: 4.2.2014

Fortschr Röntgenstr 2014; 186:

680-685 @ Georg Thieme

Verlag KG Stuttgart · New York · ISSN 1438-9029

\section{Correspondence}

Dr. Frederike Hassepass

Department of

Otorhinolaryngology-Head and

Neck Surgery, University

Medical Center Freiburg

Killianstraße 5

79106 Freiburg

Germany

Tel.: ++ 49/7 61/27042010

Fax: ++49/7 61/27040750

frederike.hassepass@

uniklinik-freiburg.de

\section{Abstract \\ $\nabla$}

Purpose: Cochlear implantation $(\mathrm{CI})$ represents the gold standard in the treatment of children born deaf and postlingually deafened adults. Initial magnetic resonance imaging (MRI) was contraindicated in CI users. Meanwhile, there are specific recommendations concerning MRI compatibility depending on the type of CI system and the device manufacturer. Some CI systems are even approved for MRI with the internal magnet left in place. The aim of this study was to analyze all magnet revision surgeries in $\mathrm{CI}$ patients at one $\mathrm{CI}$ center and the relationship to MRI scans over time.

Materials and Methods: Between 2000 and 2013, a total of 2027 CIs were implanted. The number of magnet dislocation (MD) surgeries and their causes was assessed retrospectively. Results: In total 12 cases of MD resulting from an MRI scan (0.59\%) were observed, accounting for $52.2 \%$ of all magnetic revision surgeries. As per the labeling, it was considered safe to leave the internal magnet in place during MRI while following specific manufacturer recommendations: MRI intensity of 1.5 Tesla ( $\mathrm{T})$ and compression head bandage during examination.

Conclusion: A compression head bandage in a 1.5 T MRI unit does not safely prevent MD and the related serious complications in $\mathrm{CI}$ recipients. We recommend a Stenvers view radiograph after MRI with the internal magnet in place for early identification of MD, at least in the case of pain during or after MRI examination. MRI in CI patients should be indicated with restraint and patients should be explicitly informed about the possible risks. Recommendations regarding MRI compatibility and the handling of CI patients issued with MRI for the most common CI systems are summarized.

Key Points:

- MRI in CI patients: manufacturer recommendations must be followed.

- Magnet dislocation due to MRI is a serious complication.

- In case of suspected magnet dislocation: Use Stenvers view radiograph for diagnosis.

- Instant presentation to a CI center is mandatory for proper management of dislocation.

- Immediate CI revision surgery must be performed in the case of magnet dislocation.

\section{Citation Format:}

- Hassepass F, Stabenau V, Arndt S etal. Magnet Dislocation: An Increasing and Serious Complication Following MRI in Patients with Cochlear Implants. Fortschr Röntgenstr 2014; 186: 680-685

\section{Zusammenfassung \\ $\nabla$}

Ziel: Das Cochlea-Implantat $(\mathrm{CI})$ repräsentiert den Goldstandard in der Therapie von gehörlos geborenen Kindern und postlingual ertaubten Erwachsenen. Initial war die Magnetresonanztomografie (MRT) bei CI-Trägern kontraindiziert. Inzwischen gibt es je nach Implantattyp unterschiedliche Richtlinien zur MRT-Tauglichkeit, sodass bei manchen Systemen sogar mit in situ belassenem internen Magneten eine MRT möglich ist. Ziel dieser Arbeit war die Analyse aller Magnetrevisionsoperationen eines CI-Zentrums bei CI-Patienten und deren Zusammenhang zu MRT-Untersuchungen im zeitlichen Verlauf.

Material und Methoden: Zwischen 2000-2013 wurden insgesamt 2027 CIs implantiert. Die Anzahl Magnetrevisionsoperationen und deren Ur- 
sachen besonders im Zusammenhang mit MRTs wurde retrospektiv ausgewertet.

Ergebnisse: Insgesamt wurden 12 Fälle einer Magnetdislokation als Folge einer MRT-Untersuchung beobachtet (0,59\%), welche 52,2\% aller Magnetrevisionsoperationen ausmachten. Die Dislokationen nach MRT traten auf, obwohl alle Sicherheitsempfehlungen des Herstellers befolgt wurden: Intensität der MRT bei 1,5-Tesla (T) und Anlage eines Druckverbands im Bereich des CI vor der Untersuchung.

Schlussfolgerung: Der teilweise von Herstellern empfohlene Kompressionsverband im 1,5-T-MRT scheint selbst bei MRTkompatiblen CIs eine Dislokation des internen Magneten und die damit einhergehenden teils schweren Komplikationen nicht vollständig auszuschließen. Wir empfehlen eine Röntgenuntersuchung nach Stenvers nach erfolgter MRT bei MR-kompatiblem $\mathrm{CI}$ und in situ belassenem Magneten zur frühzeitigen Identifizierung einer Dislokation - zumindest im Falle von Schmerzen während oder nach der MRT. Die MRT bei CI-Patienten sollte trotz inzwischen MR-kompatibler Systeme zurückhaltend indiziert und der Patient explizit über eventuelle Folgen aufgeklärt werden. Empfehlungen hinsichtlich der MRT-Kompatibilität und dem Umgang im MRT bei den gängigsten CI-Systemen werden zusammengefasst.

\section{Introduction}

$\nabla$

For approximately 25 years, cochlear implantation (CI) has been the gold standard in the surgical treatment of children born deaf and postlingually deafened adults. The CI system contains an external speech processor with a transmitter coil and a magnet that is situated over the implanted part, which has a magnet and receiver coil. Dislocation of the internal magnet (integrated in a silicone layer in the implanted part of the system) is a rare but serious complication in CI users. The symptoms usually include recurrent reddening of the skin, swelling, and infections in the region of the implantation site. In the worst case, transdermal magnet extrusion through the scalp can occur if the dislocation goes undetected and untreated [1-3] ( $\bullet$ Fig. 1). It must be taken into consideration that infections can travel along the implant and the electrode into the cochlea thus paving the way for meningitis. Magnet dislocation was originally primarily seen in pediatric CI patients following head trauma [2]. In 2005 Migrirov and Kronenberg described magnet dislocations in $1.6 \%$ of 125 CI users (Cochlear Nucleus ${ }^{\circledR} 24$, Cochlear Ltd, Lane Cove, Australia) [4]. All dislocations were caused by head trauma. Internal magnet dislocation represents an urgent indication for surgery with reimplantation of the magnet.

As a result of the expanded indications for CI treatment, an increasing number of patients have received a $\mathrm{CI}$. In addition, the age of $\mathrm{CI}$ users is increasing due to demographic development. This results in a greater risk of comorbidities implying an increase in diagnostic procedures including imaging. The indications for MRI are also being expanded so that MRI is now often the gold standard for many medical issues.

Due to the magnetic forces and the magnetic moment acting upon both the internal magnet and the additional ferromagnetic parts of the implanted portion of the CI system, MRI examinations were contraindicated in CI patients for a

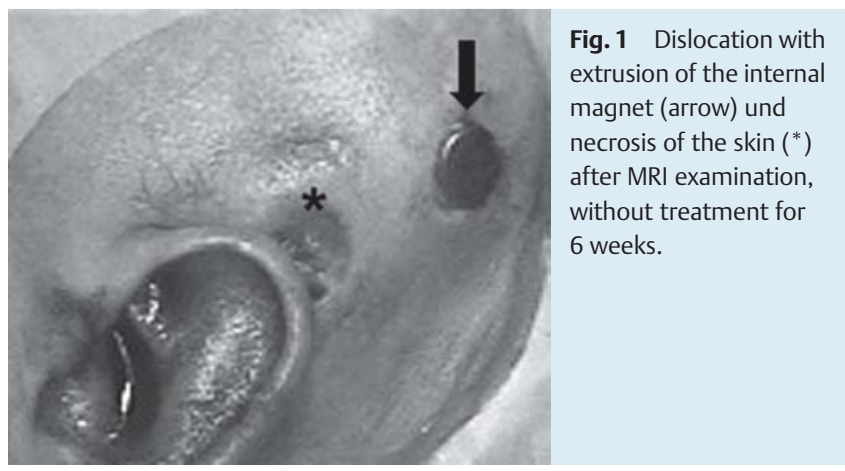

long time. The extensively described interactions between MRI and CI systems include heating of the implant, induction of electrical currents that can result in damage or malfunctions in the implant, and demagnetization of the internal magnet $[5,6]$. Therefore, explantation of the internal magnet prior to MRI examination and reimplantation after MRI is indicated for some implants when the implant design allows this and when permitted by the manufacturer. Optimized CI designs resulted in some CI systems being classified as MRI-compatible under certain conditions [79]. However, there are significant differences in this regard among the three leading manufacturers (Cochlear Limited, Sydney, Australia; Med-EL GmbH, Vienna, Austria; Advanced Bionics ${ }^{\circledR}$ Corporation, Valencia, USA). In addition, the recommendations for newer implants differ greatly from those of previous models. For several implant types, a magnet-stabilizing compression bandage must be applied prior to MRI examination. The bandage technique was described in 2006 by Gubbels and McMenomey. No interference or complications in the case of internal magnets left in place were seen in their collective during and after MRI examination [7]. There are still implants that require surgical removal of the internal magnet prior to MRI (Advanced Bionics). In addition, in the case of Advanced Bionics systems and some Med-El systems, the company is to be contacted prior to MRI examinations (refer to 0 Table 1 for a summary of the leading CI systems and their MRI compatibility).

Despite MRI compatibility with internal magnets left in place, the literature contains individual cases of magnet dislocation and skin reaction following a $1.5 \mathrm{~T}$ MRI scan using the recommended compression head bandage $[10,11]$.

The current retrospective study analyzes the frequency of magnet revision surgery and the causes particularly in relation to MRI examinations over time. In particular, the authors' experience with dislocation of the internal CI magnet after MRI and recommendations for performing MRI scans in CI users are discussed and summarized.

\section{Materials and Methods \\ $\nabla$}

All CI patients who received an implant between January 2000 and May 2013 at the University Ear, Nose, and Throat Clinic in Freiburg, Germany were analyzed. A retrospective evaluation of this collective regarding the performed magnet revision surgeries was performed particularly in rela- 
Table 1 Summary of leading $\mathrm{Cl}$ systems and their MRI compatibility. No liability assumed.

\begin{tabular}{|c|c|c|}
\hline Manufacturer/Cl system & MRI field strength & Manufacturer recommendations \\
\hline \multicolumn{3}{|l|}{ Cochlear $^{\circledR}$} \\
\hline \multirow{3}{*}{ 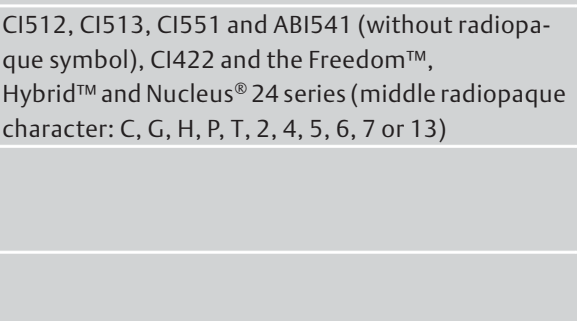 } & $\begin{array}{l}\text { more than } 1.5 \mathrm{~T} \text { up to and } \\
\text { including } 3 \mathrm{~T}\end{array}$ & $\begin{array}{l}\text { The magnet must be surgically removed for MRI. } \\
\text { Not necessary to contact manufacturer prior to MRI examination. }\end{array}$ \\
\hline & $\begin{array}{l}\text { more than } 0.2 \mathrm{~T} \\
\text { up to and including } 1.5 \mathrm{~T}\end{array}$ & $\begin{array}{l}\text { The magnet may be left in place. } \\
\text { Bandage according to } 0 \text { Fig. } 5 \text { required. } \\
\text { Not necessary to contact manufacturer prior to MRI examination. }\end{array}$ \\
\hline & 0.2 Tor less & $\begin{array}{l}\text { The magnet may be left in place. Bandage not required. } \\
\text { Not necessary to contact manufacturer prior to MRI examination. }\end{array}$ \\
\hline \multirow[t]{2}{*}{$\begin{array}{l}\text { Nucleus }^{\circledR} 22 \text { with removable magnet } \\
\text { (middle radiopaque character: } L \text { or } \mathrm{J} \text { ) }\end{array}$} & up to and including $1.5 \mathrm{~T}$ & $\begin{array}{l}\text { The magnet must be surgically removed for MRI. } \\
\text { Not necessary to contact manufacturer prior to MRI examination. }\end{array}$ \\
\hline & other field strengths & MRI is contraindicated. \\
\hline Nucleus ${ }^{\circledR} 22$ without removable magnet & all field strengths & MRI is contraindicated. \\
\hline \multicolumn{3}{|l|}{ Med-EL ${ }^{\circledR}$} \\
\hline C40, C40 +, Pulsar, Sonata and Concerto & $0.2,1.0$ and $1.5 \mathrm{~T}$ & $\begin{array}{l}\text { OP > }=6 \text { months earlier. } \\
\text { Not necessary to contact manufacturer prior to MRI examination. } \\
\text { The thickness of the bone layer beneath the implant must be at least } \\
0.4 \mathrm{~mm} \text {. } \\
\text { Bandage necessary at } 1.0 \mathrm{~T} \text { and } 1.5 \mathrm{~T} \text {. } \\
\text { The longitudinal axis of the head must be parallel to the main magnet field } \\
\text { (patient on back looking straight ahead). }\end{array}$ \\
\hline C 25C6 & all field strengths & Contact manufacturer prior to MRI examination. \\
\hline \multicolumn{3}{|l|}{ Advanced Bionics ${ }^{\circledR}$} \\
\hline $\begin{array}{l}\text { HiRes } 90 \mathrm{k} \\
\text { HiRes90k Advantage } \\
\text { (Titanium, } 2003 \text { to today) }\end{array}$ & up to and including $1.5 \mathrm{~T}$ & $\begin{array}{l}\text { Contact Advanced Bionics }{ }^{\circledR} \text { at least } 48 \text { hours prior to MRI examination. } \\
\text { The magnet must be surgically removed for MRI. }\end{array}$ \\
\hline C1.2 and C2 implants (ceramic until 2003) & all field strengths & MRI is contraindicated. \\
\hline
\end{tabular}

tion to MRI examination. The frequency of magnet revision surgery ( $\bullet$ Fig. 2) and magnet dislocation was evaluated. For a long time, MRI was absolutely contraindicated for CI users. According to manufacturer recommendations for the corresponding CI system, MRI was performed at our clinic starting in 2004 after explantation of the internal magnet and subsequent reimplantation. The surgery (explantation and reimplantation) was performed under local anesthesia on the same day as the MRI examination to reduce the risk of infection of the implant site. After various implants were approved for 1.5 T MRI, MRI scans were performed starting in 2009 in our clinic without prior magnet explanation with the corresponding specific precautions.

\section{Results}

2027 CIs were implanted from January 2000 to May 2013. In total, magnet revision surgery was indicated in 23 cases (22 CI patients). Direct head trauma was the reason for three of these revision surgeries (13.0\%). All other magnet revision surgeries are related to MRI examinations. MRI after explantation of the internal magnet and subsequent reimplantation affected 8 patients in the above collective (34.8\% of all magnet revision surgeries) who were all operated on between 2004 and 2009. In total, 12 magnet dislocations (0.59\%) occurred between 2009 and 2013 as a result of interference between the internal magnet and the 1.5 T MRI unit as a consequence or complication during MRI examination with consecutive magnet revision surgery. With $52.2 \%$, this is the main cause of all magnet revi- sion surgeries. The dislocated CI systems were as follows: 6 magnet dislocations for the Cochlear CI512, 5 for the Cochlear Nucleus Freedom and 1 for the Cochlear CI422. The affected CIs were labeled by the manufacturer as being MRI-compatible with the magnets left in place. Therefore, surgical intervention was not performed prior to MRI. In 10 of the indicated magnet dislocations (2009-2011), the examination was performed in the hospital's own radiology clinic. The specific recommendations of the CI system manufacturer were strictly followed in these cases. The speech processor was removed during the examination in each case. 2 patients were examined at an outpatient radiology center in 2013. The distribution of the magnet revision surgeries between 2000 and 2013 is summarized in - Fig. 3. According to the patient history, a compression bandage was also used in these cases. A Stenvers view radiograph was performed after MRI in the case of clinical suspicion of magnet dislocation for confirmation purposes (॰ Fig.4). All MRI examinations were reviewed strictly with respect to indication after other imaging modalities had been considered.

In the case of magnet dislocation due to MRI, magnet revision surgery was performed ( $\bullet$ Fig. 2 ). After a small incision was made in the skin occipital to the silicone body of the $\mathrm{CI}$, the original magnet was reimplanted with the administration of antibiotics (10/12 cases). The CI was explanted while leaving the intracochlear electrode array in place in one $\mathrm{CI}$ patient due to magnet extrusion with skin infection in order to reduce the risk of transfer of the infection. In addition, systemic antibiotic therapy was administered. A new CI was able to be implanted 6 weeks after treatment. 


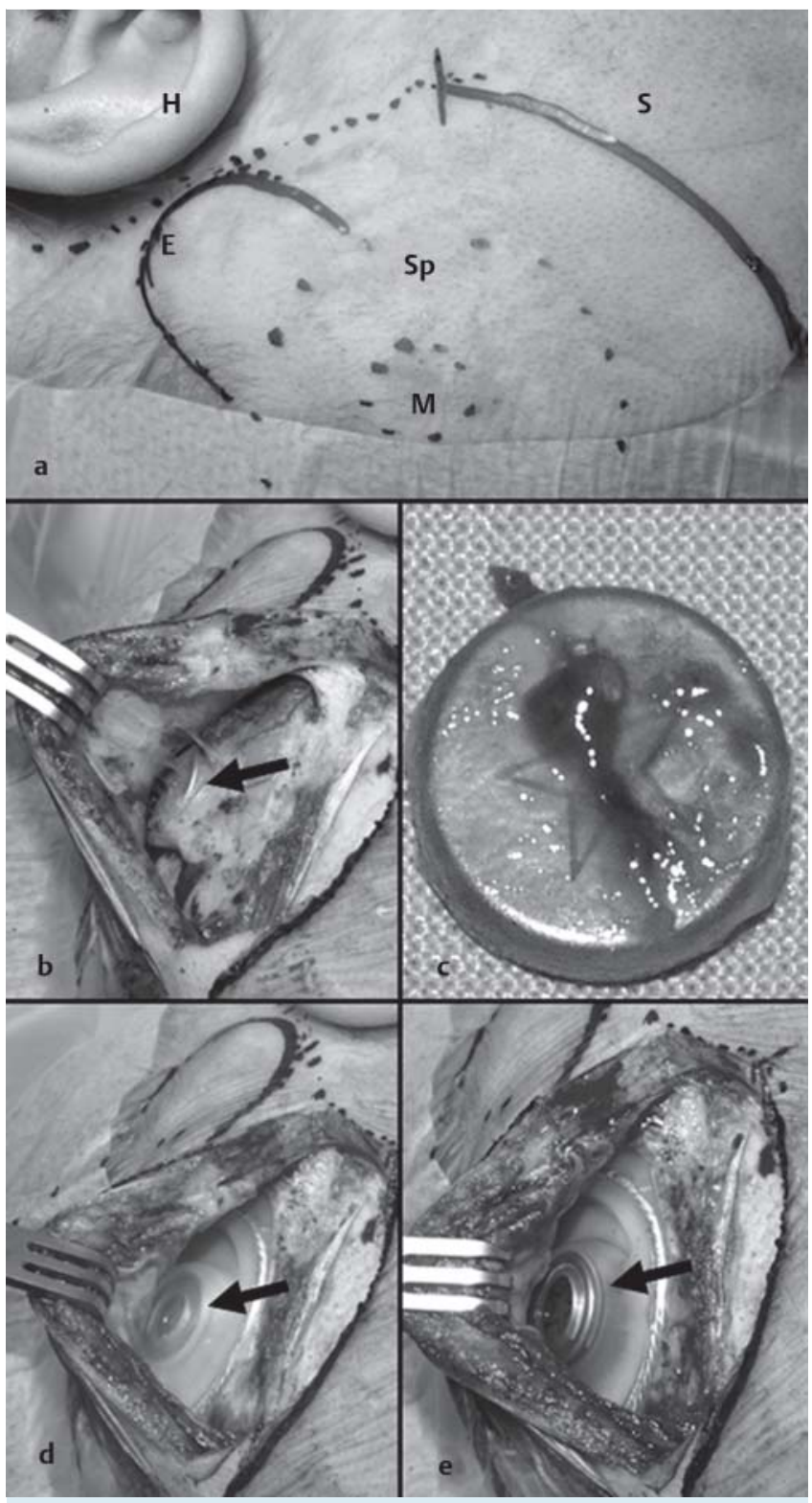

Fig. 2 Revision surgery in case of magnet dislocation and magnet explantation prior to MRI with consecutive re-implantation, a $\mathrm{S}=$ incision line parietal, cranial of implant. $\mathrm{H}=$ helix, $\mathrm{Sp}=$ area of internal coil, dotted, $\mathrm{M}=$ magnet, $\mathrm{E}=$ receiver/microchip, $\mathbf{b}$ after incision of the skin, arrow = magnet outside the silicone boundary, $\mathbf{c}$ internal magnet explanted; $\mathbf{d}$ silicone boundary without internal magnet, e closure of implant side after reimplantation of internal magnet.

In a further case, the implant was moved and antibiotic therapy was performed due to the start of an infection in the region of the dislocated magnet. No equipment failure or demagnetization due to MRI examination was seen.

\section{Discussion}

$\nabla$

Dislocation of the internal magnet is a rare but serious complication in CT users and requires revision surgery. This entails opening of the implant site thus providing potential germs indirect access to the meninges via the intracochlear electrode array. The consequences of an untreated magnet

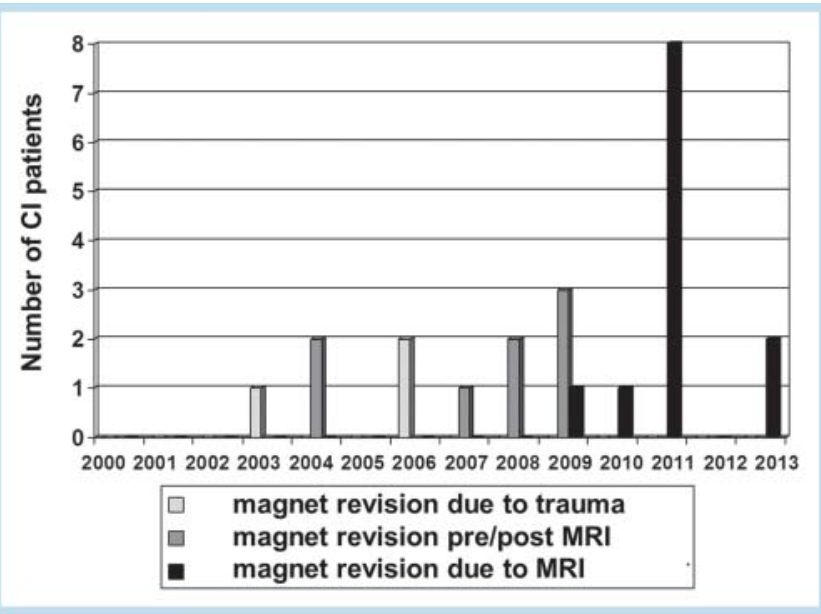

Fig. 3 Distribution of magnet revision surgery during 2000 - 2013. Pre/ Post = planned magnet explantation prior to MRI with consecutive re-implantation.

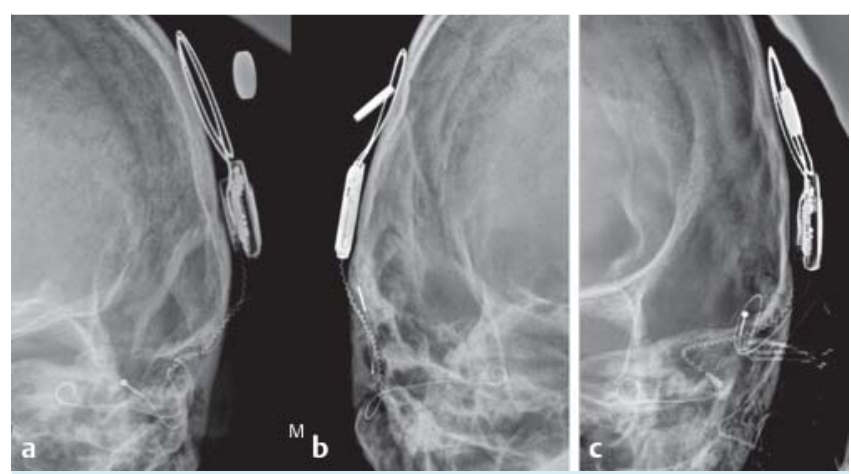

Fig. 4 Stenvers view radiograph (modified). a, b tilted magnet outside of internal coil and silicone boundary. Diagnosis: magnet dislocation. c normal finding.

dislocation can be serious and can result in complete magnet extrusion through the scalp [1 - 3]. Head trauma was considered one of the main causes of magnet migration in the past. Small children in particular are affected more frequently due to the higher probability of minor head injuries compared to adults $[3,11,12]$. In the present retrospective study, head trauma was the reason for magnet revision surgery in only $13.0 \%$ of the cases.

The majority of magnet revision surgeries and magnet dislocations were due to MRI examination. MRI is contraindicated in earlier implant generations. Extensive studies were able to show MRI safety for more sophisticated implant designs so that limited MRI application in CT patients (depending on the type of implant) is now permitted [7, 13, 14]. Starting in 2004, magnet revision surgery with explantation of the internal magnet prior to MRI examination and subsequent reimplantation was performed at our hospital in CI patients (when possible and permitted for the corresponding implant). This method is also selected if it is necessary to visualize the entire skull without artifacts. The operation can be performed with a small incision in the skin under local anesthesia. Explantation of the internal magnet and reimplantation after MRI were to be performed on the same day to keep the risk of infection as low as pos- 
sible $[15,16]$. In the present collective, this method was performed in 8 cases among $2027 \mathrm{CI}$ operations in the period between 2004 and 2009 and resulted in $34.8 \%$ of all magnet revision surgeries. However, every operation on an implanted $\mathrm{CI}$ has a risk of infection at the operation site. Moreover, explantation of the magnet results in weakening of the silicone pocket and thus increases the risk for a recurrence of dislocation $[11,17]$. These factors initially seem to support the attractiveness of MRI examinations without removal of the magnet. In relation to special implant types, multiple in vitro and in vivo studies were able to show that MRI examinations can be performed safely if the magnet remains in the silicone pocket. However, special implant-dependent precautions must be taken: For example, no field strengths above 1.5T; use of a compression head bandage; prior comprehensive patient counseling $[7,15,16,18]$. In the case of an indicated MRI examination, this bandage technique was used without prior explantation of the internal magnet starting in 2009 at our clinic, provided that the particular CI system was approved. This is the main indication for magnet revision surgery in the present retrospective analysis. In total, 12 of the 23 magnet revision surgeries (52.2\%) were performed to correct magnet dislocation caused by a 1.5 T MRI scan. To date, there are only two individual case reports in this regard in the literature $[10,11]$. Overheating of the implant, implant defects and demagnetization, which are specified in the literature in the case of higher field strengths, were not observed in the present collective [5, 6]. At first glance, the magnet dislocation rate after MRI of $0.59 \%$ in the present study does not seem particularly high (12 cases among 2029 implanted CIs). However, all CIs were classified as MRI-compatible and the specific recommendations of the manufacturer were strictly followed in at least 10 of the 12 cases. There is a clear increase in the occurrence of magnet dislocation following MRI with a jump in the year $201183.3 \%$ of the magnet dislocations after MRI occurred between 2011 and 2013 ( $\bullet$ Fig.3). The various reasons for this increase need to be discussed.

The bandage technique was first introduced at our clinic in 2009 and was initially only indicated on a limited basis so that corresponding complications could only be seen starting in 2009. Moreover, there is an increase in MRI examinations in general due to the expanded indications for MRI scans. A British study predicts that the lifetime prevalence of neurological diseases requiring MRI of the skull is $6.25 \%$ [19].

All dislocations during MRI occurred in Cochlear ${ }^{\circledR}$ implants. This can be partly attributed to the fact that the majority of our patients chose Cochlear ${ }^{\circledR}$ implants preoperatively (87.1\% of all CI users between 2000 and 2013). In addition, CIs from this manufacturer are MRI-compatible to $1.5 \mathrm{~T}$ (if the CI system was implanted after 1996) in contrast to CIs from Advanced Bionics, for example, which are not approved for MRI examinations with the magnet left in place. As a result of the frequency of magnet dislocations despite the use of the bandage technique during 1.5 T MRI particularly in the year 2011, Cochlear ${ }^{\circledR}$ modified the original guidelines since the recommended bandage technique could no longer be considered sufficient [20]. The recommendations for performing MRI in CI patients with a newer Cochlear $^{\circledR}$ CI system (CI512, CI513, CI551, CI422 and the Freedom ${ }^{\mathrm{TM}}$, Hybrid ${ }^{\mathrm{TM}}$ und Nucleus ${ }^{\circledR} 24$ series; refer to
- Table 1) now include application of a splint directly on the scalp over the internal magnet in addition to the compression bandage [21]. This is made of a folded piece of paper, a plastic card, or a self-hardening adhesive (refer to - Fig. 5 for details). The modification of the compression bandage seems to minimize the dislocation risk since it prevents possible rotation and shear movements of the internal magnet. At least, no additional MRI-based magnet dislocations have occurred at the University Freiburg during MRI examination of patients with a Cochlear ${ }^{\circledR}$ CI system since the introduction of the splint technique at the beginning of 2013 ( $n=3$ patients). The two described cases of MRI-based magnet dislocation in 2013 did not occur at our hospital. Both patients indicated that they wore a circular head bandage without application of a special splint over the magnet.

To verify the diagnosis in the case of clinical suspicion of magnet dislocation after MRI, a Stenvers view radiograph, which showed a dislocated magnet as diagnosis confirmation in every case, was acquired in the present collective.

The limitation of the present retrospective study is the lack of opportunity to specify the incidence of magnet dislocation in CI patients due to MRI. The total number of MRI examinations performed among our 2027 CI patients, including the complication-free MRI scans, could not be retrospectively determined. If this data had been available for analysis, the frequency and the individual risk of magnet dislocation in the case of MRI could have been specified. The assessment would also simplify indication determination and the counseling of $\mathrm{CI}$ patients prior to an MRI examination. The ideal situation in the clinical routine would include standardized documentation of MRI examinations in $\mathrm{CI}$ patients including the protocol used, the indication, and the use of the bandage technique according to the guidelines in order to provide an exact representation of the incidence of magnet dislocation and other complications such as heating of the implant. It is questionable whether clinical implementation of such follow-up is possible, primarily if CI patients undergo MRI examination at another radiology clinic or outpatient practice. In our experience, radiologists working outside of $\mathrm{CI}$ centers or on an outpatient basis are very conservative with MRI examinations in CI patients and recommend having examinations performed at the $\mathrm{CI}$ clinic's radiology department. Moreover, $\mathrm{CI}$ clinics and CI manufacturers are often contacted by radiologists for advice in the case of questions regarding MRI guidelines in CI patients. Even without specification of the incidence, the present data show the necessity for precise and careful handling before and during MRI examination.

Examining radiologists should always consider possible magnet dislocation in $\mathrm{CI}$ patients with magnets left in place during MRI examination. In the case of pain during or after MRI examination or problems connecting to the external speech processor, we recommend immediately performing a Stenvers view radiograph in order to ensure prompt diagnosis. Moreover, treatment ideally at the responsible $\mathrm{CI}$ clinic should be initiated immediately in the case of patients with magnet dislocation in order to avoid serious complications. It remains to be seen whether the above modification can reliably prevent magnet dislocation caused by MRI examination. Further research in the field of magnet and silicone pocket design and optimized guidelines for MRI ex- 


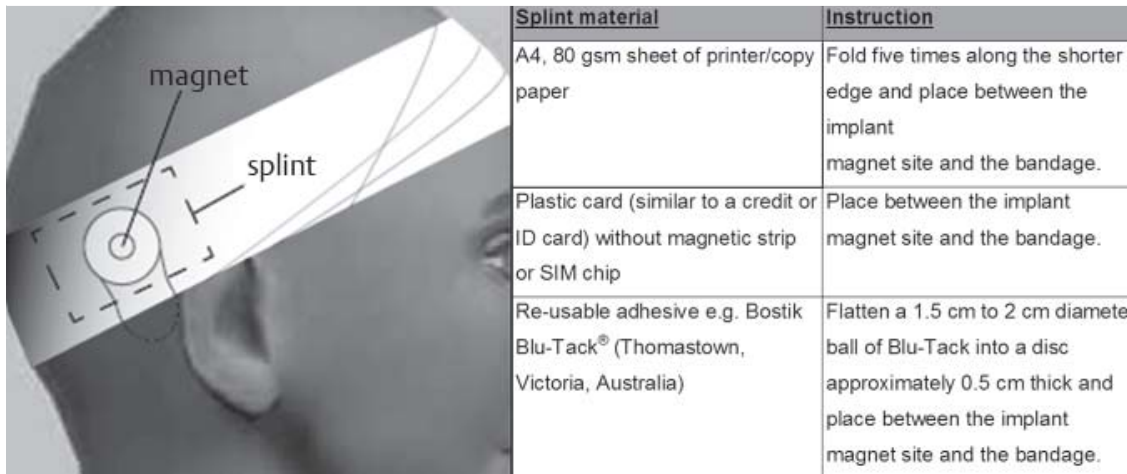

Fig. 5 Recommendation for $\mathrm{Cl}$ fixation prior to MRI: elasticized compression bandage (max. width of $10 \mathrm{~cm} / 4 \mathrm{in}$.) applied circularly over the implant and therefore the internal magnet with full stretching of the bandage and fixation with a adhesive tape. This should be done shortly before MRI because patients feel uncomfortable with it. Specific recommendations by Cochlear $^{\circledR}$ with the innovation of providing stiffening via a splint were introduced in 2012 [20]. A circular bandage (without splint) is recommended in the same way for other implants. (Image courtesy by Cochlear ${ }^{\circledR}$ ).

amination in CI users are necessary before additional recommendations can be made.

\section{Summary \\ $\nabla$}

Magnet dislocation is a serious complication in CI users that can occur with greater frequency during MRI examination. The examining radiologist should be aware of this risk even if the patient has an MRI-compatible CI. The particular recommendations of the manufacturer must be strictly followed. The user manual of the CI system or the manufacturer can provide support in this regard. A Stenvers view radiograph can confirm the diagnosis of magnet dislocation and prompt reimplantation of the magnet at a CI center can prevent local complications.

\section{Relevance of the study}

- There is an increasing number of MRI examinations in cochlear implant patients

- There is a risk of subcutaneous magnet dislocation during MRI examination and if left untreated the dislocation can result in serious complications

- Precautions and recommendation of the manufacturer must be strictly followed

\section{References}

1 Yohn DC, Maessen H, Morris DP. Cochlear implant magnet extrusion with subsequent surgical replacement and restoration of full implant use without the need for device explantation. Cochlear Implants Int 2011; 12: 244-247

2 Wild C, Allum J, Probst $R$ et al. Magnet displacement: a rare complication following cochlear implantation. Eur Arch Otorhinolaryngol 2010; 267: 57-59

3 Wilkinson EP, Dogru S, Meyer TA et al. Case report: Cochlear implant magnet migration. Laryngoscope 2004; 114: 2009-2011

4 Migirov L, Kronenberg J. Magnet displacement following cochlear implantation. Otol Neurotol 2005; 26: 646-648

5 Teissl C, Kremser C, Hochmair ES et al. Magnetic resonance imaging and cochlear implants: compatibility and safety aspects. J Magn Reson Imaging 1999; 9: 26-38
6 Portnoy WM, Mattucci K. Cochlear implants as a contraindication to magnetic resonance imaging. Ann Otol Rhinol Laryngol 1991; 100: 195-197

7 Gubbels SP, McMenomey SO. Safety study of the Cochlear Nucleus 24 device with internal magnet in the 1.5 Tesla magnetic resonance imaging scanner. Laryngoscope 2006; 116: $865-871$

8 Heller JW, Brackmann DE, Tucci DL et al. Evaluation of MRI compatibility of the modified nucleus multichannel auditory brainstem and cochlear implants. Am J Otol 1996; 17: 724-729

9 Chou CK, McDougall JA, Can KW. Absence of radiofrequency heating from auditory implants during magnetic resonance imaging. Bioelectromagnetics 1995; 16: 307-316

10 Broomfield SJ, Da Cruz M, Gibson WP. Cochlear implants and magnetic resonance scans: A case report and review. Cochlear Implants Int 2013; $14: 51-55$

11 Deneuve S, Loundon $N$, Leboulanger $N$ et al. Cochlear implant magnet displacement during magnetic resonance imaging. Otol Neurotol 2008; 29: 789-1190

12 Migirov L, Kronenberg J. Magnet displacement following cochlear implantation. Otol Neurotol 2005; 26: 646-648

13 Wackym PA, Michel MA, Prost RW et al. Effect of magnetic resonance imaging on internal magnet strength in Med-El Combi 40+ cochlear implants. Laryngoscope 2004; 114: 1355 - 1361

14 Weber BP, Goldring JE, Santogrossi T et al. Magnetic resonance imaging compatibility testing of the Clarion 1.2 cochlear implant. Am J Otol 1998; 19: 584-590

15 Crane BT, Gottschalk B, Kraut M et al. Magnetic resonance imaging at 1.5 T after cochlear implantation. Otol Neurotol 2010; 31: 1215-1220

16 Sonnenburg RE, Wackym PA, Yoganandan $N$ et al. Biophysics of cochlear implant/MRI interactions emphasizing bone biomechanical properties. Laryngoscope 2002; 112: 1720-1725

17 Yun JM, Colburn MW, Antonelli PJ. Cochlear implant magnet displacement with minor head trauma. Otolaryngol Head Neck Surg 2005; 133: $275-277$

18 Baumgartner WD, Youssefzadeh S, Hamzavi J et al. Clinical application of magnetic resonance imaging in 30 cochlear implant patients. Otol Neurotol 2001; 22: 818-822

19 MacDonald BK, Cockerell OC, Sander JW et al. The incidence and lifetime prevalence of neurological disorders in a prospective communitybased study in the UK. Brain 2000; 123: 665-676

20 Jeon JH, Bae MR, Chang JW et al. Reversing the polarity of a cochlear implant magnet after magnetic resonance imaging. Auris Nasus Larynx 2012; 39: 415-417

21 http://www.cochlear.com/wps/wcm/connect/d4c7f616-4345-4bd2b91b-0d3526e5165f/de_global_warnings_german_234569_ISS6_MAR13_translation_of_249170_ISS6_545kb.pdf?MOD=AJPERES\&CONVERT_TO=url\&CACHEID $=\mathrm{d} 4 \mathrm{c} 7 \mathrm{f} 616-4345-4 \mathrm{bd2}-\mathrm{b} 91 \mathrm{~b}-$ 0d3526e5165f 